\title{
TECNOLOGIA DA INFORMAÇÃO COMO FERRAMENTA PARA A LOGÍSTICA
}

\author{
https://dx.doi.org/10.48097/2674-8673.2021n5p16
}

\author{
Arandi Maciel Campelo ${ }^{1}$ \\ Lucas Emanuel Sousa da Veiga Pessoa ${ }^{2}$ \\ Matheus Rebelo Vilarim Pires ${ }^{3}$
}

\section{RESUMO}

Atualmente a tecnologia vem auxiliando o homem a alcançar resultados nunca vistos antes na história. Cabe ao mesmo saber como lidar com essa tecnologia a sua volta e usá-la de forma correta para assim chegar ao seu objetivo de forma rápida, fácil e com o mínimo de esforço possível. Com os avanços dos métodos computacionais nas últimas décadas, tal fenômeno proporcionou o desenvolvimento de novas ferramentas que servem de apoio para as práticas logísticas, trazendo assim pontos positivos na execução e no controle, proporcionando assim o seu desenvolvimento. A tecnologia hoje vem desempenhando um papel de destaque dentro das organizações, oferecendo ferramentas de natureza computacional aos métodos logísticos que são empregados nas empresas. Foi possível observar na pesquisa os benefícios de sua adoção por parte das organizações, uma vez que suas ferramentas se tornam vitais para o sucesso dentro de um mercado cada vez mais competitivo. Este artigo foi construído a partir de pesquisas bibliográficas realizada em 2020, tendo como principais fontes Ballou (2006) e Arozo (2003). A pesquisa revelou que é de suma importância a área de Tecnologia da Informação (TI) focada nos processos logísticos, pois agiliza cada vez mais os diversos setores de uma empresa.

Palavras-chave: Tecnologia da Informação. Logística. Ferramentas tecnológicas.

Data de submissão: 17/03/2021

Data de aprovação: $27 / 04 / 2021$

\begin{abstract}
Nowadays technology has been helping man to achieve results never seen before in history. It is also up to you to know how to deal with this technology around you and use it correctly in order to reach your goal quickly, easily and with the least possible effort. With the advances in computational methods in recent decades, this phenomenon has provided the development of new tools that support logistical practices, thus bringing positive points in execution and

\footnotetext{
${ }^{1}$ Orientador: Doutor em Educação - Universidade Federal de Pernambuco; Administrador - Universidade de Pernambuco - FCAP/UPE; Mestre em Planificación y Gestion Organizacional - Universidad Autonoma de Madrid / Espanha; Mestre em Dirección y Organización de Hospitales y Servicios de Salud - Universidad Politécnica de Valencia / Espanha; Especialista em Marketing - FCAP/UPE; Consultor em Sistemas Organizacionais, desde 1984; Professor e Diretor Acadêmico da Faculdade Metropolitana da Grande Recife. Email: arandi.campelo@globo.com

${ }^{2}$ Estudante do curso de Tecnólogo em Logística, da Faculdade Metropolitana da Grande Recife. E-mail: lucascerde@gmail.com

${ }^{3}$ Estudante do curso de Tecnólogo em Logística, da Faculdade Metropolitana da Grande Recife.

E-mail: Matheus_jynx@hotmail.com
} 
control, thus providing their development. Technology today has played a prominent role within organizations, offering computational tools to the logistical methods that are employed in companies. It was possible to observe in our research the benefits of its adoption by organizations, since its tools become vital for success in an increasingly competitive market. This article was built from bibliographic research carried out in 2020, with Ballou (2006) and Arozo (2003) as its main sources. The research revealed that the area of Information Technology (IT) focused on logistics processes is extremely important, as it increasingly streamlines the various sectors of a company.

Keywords: Information Technology. Logistics. Technological tools.

\section{INTRODUÇÃO}

Hoje os avanços tecnológicos tem proporcionado à humanidade um patamar de informação jamais visto antes na história da humanidade. $\mathrm{O}$ mundo tornou-se um espaço onde tudo está interligado. Grande parte desse nível de informação se deve à evolução computacional e à rede mundial de computadores.

\footnotetext{
A evolução da tecnologia da informação tornou possível um meio global de comunicação com total disponibilidade de informação, juntamente com a estabilidade de informações, juntamente com o estabelecimento de uma nova fronteira digital, para caminhar na direção de uma economia globalizada. (DI SERIO, 2001, p. 27).
}

Devido a essa evolução no nível de informação, o modo de tratamento dela também evoluiu, surgindo assim como ferramenta de tratamento dessas informações a Tecnologia da Informação. Segundo pesquisa realizada pelo SEBRAE (2008) cerca de 60\% das micro e pequenas empresas no país fazem investimentos em Tecnologia da Informação. Em 2009 esses investimentos atingiram US\$ 7,4 bilhões.

Atualmente, não basta apenas oferecer um serviço ou determinado produto para um mercado consumidor. As organizações têm que levar em conta vários estudos de mercado como, por exemplo, a condição financeira da população, como esse produto será distribuído e qual o retorno de lucro para a organização. Tais informações podem determinar a vida ou morte das empresas. A tecnologia vem atuando como um importante papel nos processos de planejamento, implementação e controle das organizações de uma forma bem satisfatória tanto para o consumidor como para as empresas que adotam essa prática.

\section{REFERENCIAL TEÓRICO}

Este quesito tem como objetivo apresentar a base teórica que sustenta o estudo proposto. Diante dessa proposição, faz-se necessário percorrer a literatura referente ao contexto de 
sistema da informação com ênfase na aplicação logística bem como ferramentas e sistemas aplicados a mesma.

\section{A LOGÍSTICA}

A logística é percebida como a competência que vincula a empresa a seus clientes e fornecedores. De acordo com o Council of Supply Chain Management Professionals CSCMP, a logística consiste no processo de planejamento, implementação e controle de forma eficiente e eficaz, do fluxo e armazenagem de produtos, serviços desde o ponto de origem até o ponto de consumo, em conformidade com as demandas do cliente.

Detalhando o conceito de logística: é a busca de otimização das atividades de processamento de pedidos, dimensionamento e controle de estoques, transporte, armazenagem e manuseio de materiais, projetos de embalagem, compras e gerenciamento de informações correlatas às atividades de forma a prover valor e melhor nível de serviço ao cliente. A busca pelo ótimo padrão dessas atividades é orientada para a racionalização máxima do fluxo do produto/serviço do ponto de origem ao ponto do consumo final, portanto, ao longo de to da a cadeia de suprimentos. (SALLES, 2000, p. 57).

Para Ballou (2006), a logística deve ser entendida a partir de uma visão sistêmica na qual:

\footnotetext{
A logística é um conjunto de atividades funcionais inter-relacionadas (transportes, controles de estoques, etc.), que se repetem inúmeras vezes ao longo do canal pelo qual matérias-primas vão sendo convertidas em produtos acabados, aos quais se agrega valor ao consumidor. (BALLOU, 2006, p. 29).
}

Pode-se definir logística como sendo a união de quatro atividades básicas: as de aquisição, movimentação, armazenagem e entrega de produtos. O termo logístico, de acordo com o dicionário Aurélio, vem do Francês logistique e tem como uma de suas definições: parte da arte da guerra que trata do planejamento e da realização de projetos e desenvolvimento, obtenção, armazenamento, transporte, distribuição, reparação, manutenção e evacuação de material para fins operativos ou administrativos. (AURÉLIO, 2007).

Nas organizações atuais, sendo elas públicas ou privadas, podemos observar uma interligação do mercado onde todos dependem de todos, sendo uma hora ofertante, outra hora ofertada por serviços ou produtos. O uso dos serviços logísticos está presente em empresas de transportes, alimentícias, forças armadas, serviços postais, distribuição de petróleo, transporte público, e muitas outras. Toda essa integração chama-se mercado globalizado. Uma boa consistência das informações soa de fundamental importância no mercado tanto para a 
obtenção de informações como para a disponibilização de serviços provenientes das necessidades observadas no mercado.

A logística tem como foco principal a diminuição de gastos para as empresas, aumentando a rentabilidade das atividades exercidas, sendo essas das obtenções ou distribuição e armazenagem, tornando assim algo fundamental tanto para as organizações quanto para os clientes, pois se mostra eficaz na busca de soluções para tais problemas de mercado.

Atualmente, as organizações têm sido desafiadas a operar de forma eficiente e efic az, buscando um diferencial que a faça garantir a continuidade de suas atividades dentro de um mercado cada vez mais exigente e competitivo. A logística realmente vem sendo uma atividade implementada com sucesso. Várias empresas que visam aumentar a rentabilidade de suas atividades modernizam seu modelo logístico.

\section{TECNOLOGIA DA INFORMAÇÃO}

A Tecnologia da Informação (TI) ou, em inglês, Information Technology (IT), pode ser definida como o conjunto de todas as atividades e soluções providas por recursos computacionais que visam permitir a obtenção, o armazenamento, a proteção, o processamento, o acesso, o gerenciamento e o uso das informações.

Esse conjunto de soluções é composto, essencialmente, por uma combinação de equipamentos (hardware) e de programas ou aplicativos (software).

a) Hardware: PCs, notebooks, servidores, tablets, smartphones, equipamentos de redes (como roteadores e switches), impressoras, leitores de códigos de barra, entre outros;

b) Software: sistemas operacionais, aplicativos (programas), protocolos de comunicação, antivírus, soluções de ERP, certificados digitais, tecnologias como blockchain, e outros.

\section{Evolução da Tecnologia da Informação}

A importância da informação no mercado tão globalizado como nos dias de hoje é um dos protagonistas pelo crescimento do mercado de TI. A tecnologia da informação pode ser decisiva para o sucesso ou fracasso de uma empresa, contribuindo assim para que a organização seja ágil, flexível e forte.

Os computadores surgiram de forma rudimentar e hoje permitem uma melhor integração entre os usuários e os especialistas de TI, abrindo caminhos para novas descobertas 
tecnológicas. Definitivamente, os microcomputadores ganharam espaço e tornaram-se popularizados devido ao preço e à capacidade de armazenamento de informação. O principal propósito de coletar, manter e manipular os dados dentro da empresa é o de auxiliar a tomar decisões, abrangendo desde o estratégico até o operacional. Estas atividades foram conduzidas informalmente por vários anos. Entretanto, com a disponibilidade de computadores de alta velocidade, que possuem capacidade de armazenagem de dados cada vez maior, os procedimentos em torno do manuseio de dados tornaram-se mais estruturados. (BALLOU, 2001, p. 109).

Os computadores tornaram-se muito mais velozes e de diferentes tamanhos. Seus meios de armazenamento têm maior capacidade, permitindo acessos aos dados de forma mais direta. Das tecnologias de entrada dos cartões e fitas de papel perfurado, chegou-se ao teclado, ao escaneamento óptico, e mais recentemente, ao reconhecimento de voz. Das tecnologias de saída dos relatórios impressos, evolui-se para as exibições de textos e gráficos em vídeo: os hipertextos multimídia.

Novos sistemas operacionais e programas para gerenciamento de redes locais tornaramse populares e mais fáceis de serem utilizados. Gerenciadores com novas funções e armazenamento de dados não estruturados já estão presentes no mercado.

\section{A importância da Tecnologia da Informação nas empresas}

TI é uma ferramenta essencial para as empresas, atualmente. Ela tem como objetivo aumentar o fluxo de informações trafegadas, ou seja, aumento das operações e atividades e competitividade no mercado, além de reduzir os custos da empresa, oferecendo estatísticas de crescimento em vendas, atendimento, raio de atuação, entre outros. A TI organiza as informações dentro da empresa, proporcionando rápido transporte da informação e oferecendo sigilo a dados que pertence somente à empresa.

Conforme citam Chopra e Meindln (2001), informação é essencial para tomar boas decisões de gerenciamento na cadeia de suprimentos porque ela proporciona o conhecimento do escopo global necessário para tomar boas decisões. (CHOPRA; MEINDLN 2001, p. 354).

De maneira geral, eficiência significa fazer bem as coisas, enquanto que eficácia significa fazer as coisas certas. A eficácia está associada ao uso dos recursos, enquanto a eficiência está associada com a satisfação de metas, objetivos e requisitos. A eficiência está relacionada com aspectos internos das atividades de TI e a adequada utilização dos recursos, enquanto que a eficácia confronta os resultados das aplicações de TI com os resultados no 
negócio da empresa e os possíveis impactos na sua operação e estrutura. Ser eficaz em TI significa utilizá-la para alavancar o negócio da empresa, tornando-a mais competitiva.

\section{Tecnologia da Informação na Logística}

A transferência de informações é de suma importância nas atividades logísticas, assim como os dados de clientes, controle de estoque, movimentação dentro do deposito, etc. Antigamente, estas informações eram trafegadas via papel, o que tornava a comunicação muito lenta e insegura, sujeito a erros. A transferência, armazenamento e gerenciamento informatizado dessas informações é tão eficaz quanto a prestação de serviços. Um exemplo é a troca de mensagens entre uma empresa e suas filias. Na matriz fica a TI onde são processados todos os dados das empresas, e as filias movimentam todas as vendas, o estoque, financeiro, e tudo isso através de um link que faz com que a mesma permaneça conectada. Outro exemplo é um web sites de compras em que há comodidade para o cliente fazer compras de onde estiver e o produto chegar na sua residência. Todos os processos ligados à informação e à logística estão diretamente ligados a um procedimento integrado, utilizando ferramentas informatizadas (hardware e software) para gerenciar as informações e operações em uma empresa.

De acordo com Bowersox e Closs (1996) ao abordarem a questão da necessidade de ter informações rápidas, em tempo real e com alto grau de precisão para que se possa gerir de forma eficiente a logística e a cadeia de suprimentos, apresentam três razões fundamentais:

Primeiro: clientes entendem que informações do andamento de uma ordem, disponibilidade de produtos, programação de entrega e dados do faturamento são elementos fundamentais do serviço ao cliente.

Segundo: com a meta da redução do estoque em toda a cadeia de suprimentos, os executivos percebem que com as informações adequadas eles podem, efetivamente, reduzir estoques e necessidade de recursos humanos, usando informações mais recentes, permitindo reduzir estoques através da minimização das incertezas da demanda.

Terceiro: a disponibilidade de informação, aumentando a flexibilidade com respeito ao saber quanto, quando e onde os recursos podem ser utilizados para obtenção de vantagens estratégicas. 


\section{Ferramentas de TI aplicadas à Logística}

Para que a TI tenha êxito nas execuções das tarefas é necessário definir sistemas que melhor atendem a necessidade da empresa, tendo em visita que a logística pode atuar em vários ramos e atividades. Segundo Bowersox e Closs (2001), o compartilhamento de informações gera várias vantagens como a redução do custo de processamento de pedidos, a diminuição das incertezas de planejamento e operações e a redução dos níveis de estoque.

\section{Warehouses Management System (WMS)}

Esse sistema é também conhecido como WMS. É uma tecnologia utilizada de forma gradual em armazéns, integrando e processando as informações de acordo com a localização do material. Segundo Arozo (2003), estes sistemas são responsáveis pelo gerenciamento da operação no cotidiano de um armazém. Sua utilização está restrita a decisões operacionais como, por exemplo, a definição de rotas de coleta e a definição de endereçamento dos produtos.

Conforme cita Banzato (1998), é um sistema de gestão de armazéns que aperfeiçoa todas as atividades operacionais (fluxo de materiais) e administrativas (fluxo de informações) dentro do processo de armazenagem, incluindo recebimento, inspeção, endereçamento, estocagem, separação, embalagem, carregamento, expedição, emissão de documentos, inventário, entre outras. As informações integradas atendem às necessidades logísticas, maximizando os recursos e minimizando desperdícios de tempo e de pessoas. Toda essa informação do estoque tem como ferramenta principal o coletor de dados que é um equipamento com capacidade de transmitir e receber rápidas informações de armazenagem quando conectados diretamente ao sistema através de uma rede sem fio.

\section{Enterprise Resource Planning (ERPs)}

Os sistemas empresariais (ERP) são sistemas de grande complexibilidade, integrando de forma eficaz todos os sistemas operacionais de uma empresa. Por ser um sistema que auxilia toda parte gerencial da empresa, sua adoção não é simples, exigindo da empresa pré-requisitos na sua implementação.

Podemos definir ainda que o ERP seja composto basicamente na integração de todas as atividades atuantes em uma empresa, podendo ser elas: produção, recursos humanos, finanças, transporte, etc. Tem como papel fundamental tornar o fluxo das informações algo visível e palpável, possibilitando assim uma tomada de decisão mais precisa. Esse sistema tem como 
característica a permissão de análise de custo-benefício de suas aquisições. Podemos observar algumas vantagens na sua aquisição por uma organização:

a) São desenvolvidos através de modelos padrões de processos;

b) Integram sistemas de várias áreas das empresas;

c) Utiliza um banco de dados centralizado;

d) Possuem grande abrangência funcional.

É necessário para a empresa identificar suas reais necessidades antes mesmo de pensar em adotar o sistema integrado para que assim ela possa ter sucesso na implantação do sistema. Como o projeto é de caráter amplo, a maioria das empresas perdem de vista as motivações originais e naufragam diante das dificuldades encontradas. (DEMPSEY, 1999).

\section{Customer Relationship Management (CRM)}

O CRM está relacionado principalmente à satisfação do cliente como prioridade, já que esse é um grande trunfo e garantia de sucesso de qualquer empresa. Ele possui todas as informações de dados relacionados às interações de compra e venda entre a organização e o consumidor. E, de posse destes dados, é possível prever demandas e necessidades do públicoalvo, permitindo com que a empresa se antecipe e atenda a todos esses anseios da melhor forma, aproximando e melhorando o contato com o cliente.

\section{Transportation Management System (TMS)}

O TMS é uma ferramenta de TI muito útil às transportadoras, pois ele auxilia principalmente no controle de informações relativas a fretes, entregas, eficiência de motoristas e veículos, roteiros de viagens, rastreamento das mercadorias, emissão de documentos fiscais de cargas, além de facilitar na emissão de Notas Fiscais Eletrônicas (NF-e). Ele possui também o diferencial de otimizar a qualidade e a produtividade em todo o processo de transporte, permitindo uma maior integração e controle de toda operação.

\section{Softwares de rastreamento de remessas}

Essas ferramentas estão relacionadas principalmente à comodidade de poder acompanhar todo o processo de entrega durante todo o trajeto. Com informações em tempo real sobre as compras, esse recurso otimiza tanto a relação com o cliente como organiza o trabalho das empresas. 


\section{Softwares de gestão de estoque}

Essas ferramentas de gestão de estoque fornecem informações precisas para os gestores de logística sobre a real situação do estoque. Desta forma, evita-se contratempos como a indisponibilidade de produtos ou excessos na armazenagem.

\section{Empresas Fornecedoras}

Algumas das principais empresas fornecedoras desse tipo de software no mundo já estão no Brasil. A SAP, além de ocupar a liderança mundial neste mercado, tamb ém ocupa essa posição no Brasil com 38\% das vendas de licença de software. Por outro lado, a Datasul possui o maior número de clientes, com $23 \%$ do mercado.

Alguns exemplos de sucesso da implantação de sistemas ERP:

a) Autodesk - passou a embarcar 98\% de seus pedidos dentro de 24 horas após a implantação de um ERP;

b) Votorantim - o giro do estoque melhorou de 30 a 40\% e o número de funcionários administrativos pôde ser reduzido em 30\%, resultando em ganhos de US\$ 6 milhões anuais;

c) Indústria média norte-americana de autopeças - reduziu o tempo entre o pedido e a entrega de seis para duas semanas. Outra diferença notável: a troca de documentos entre departamentos que demorava horas ou mesmo dias caiu para minutos e até segundos.

\section{METODOLOGIA}

Foi utilizado o método de pesquisa descritiva com a finalidade de analisar e explicar os sistemas da tecnologia da informação focados na área de logística. Partindo de uma revisão bibliográfica composta pelos principais autores da área, o método de análise é explicativo e de abordagem qualitativa. A experiência da pesquisa bibliográfica foi de suma importância para aguçarmos o conhecimento mais especifico dos sistemas no âmbito logístico, detalhando e definindo as operações e etapas.

\section{CONSIDERAÇÕES FINAIS}

A tecnologia pode ser considerada também como uma potente força no sentido de capacitar uma extensão nas habilidades humanas. Portanto, a tecnologia da informação deve ser vista como suporte aos processos de logística e nas decisões operacionais e de negócios 
das organizações. Um recurso tecnológico bem empregado em um ambiente empresarial pode tornar-se um grande aliado no que diz respeito às vantagens competitivas. Observa-se também outra vantagem que a tecnologia da informação fornece para a logística: uma grande perspectiva de crescimento para o mercado, justificado pelo tamanho do mercado existente, atualmente, sendo que as vantagens baseadas no crescimento da TI em logística ocorrem com o atendimento da necessidade de aquisição da tecnologia de informação para integração da cadeia produtiva, a fim de atender o cliente final.

É atualmente a fonte de vantagem competitiva mais cobiçada no mercado, porém devem ser repensados os processos organizacionais e seu redesenho. Toda a tecnologia que hoje está à disposição da solução da logística empresarial é capaz de gerar soluções que satisfaçam qualquer necessidade de mercado. De um modo geral, o sucesso da implantação de sistema logísticos nas empresas e as vantagens advindas de sua aplicação dependem do processo de amadurecimento empresarial. Dessa forma, conclui-se que a TI é peça fundamental para o crescimento das empresas que pretendem disparar na frente no mercado competitivo, podendo, assim, atender seus clientes com muito mais eficiência, eficácia e rapidez.

\section{REFERÊNCIAS}

AURÉLIO, Buarque de Holanda Ferreira. Dicionário Aurélio da língua Portuguesa. São Paulo: Positivo, 2007.

AROZO, R. (2003). Softwares de supply chain management: Definições, principais funcionalidades e implantação por empresas brasileiras. Disponível em: https://www.ilos.com.br/web/software-de-supply-chain-management-parte-1/. Acesso em: 17 jun. 2020.

BOWERSOX, Donald J.; CLOSS, David J. Logística empresarial. São Paulo: Atlas, 2001.

BOAR, Bernard H. Tecnologia da Informação. São Paulo: Berkeley, 1999.

BANZATO, E. WMS - Warehouse management system: Sistema de gerenciamento de armazéns. São Paulo: IMAN, 1998.

BALLOU, Ronald H. Logística empresarial: transporte, administração de materiais e distribuição física. 5. ed. Porto Alegre: Bookman, 2006.

CHOPRA, Sumil; MEINDL, Peter. Supply Chain Management: Strategy, Planning, and Operation. New Jersey: Prentice-Hall, Inc., 2001. 
CRUZ T. Sistemas de Informações Gerenciais: Tecnologias da Informação e a Empresa do Sec. XXI. São Paulo: Atlas, 2010.

DEMPSEY, M. Pacote de ERP não resolve tudo. Disponível em: http:// www.scielo.br. Acesso em: 12 jun. 2020.

FLEURY, P. F.; WANKE, P. Logística e gerenciamento da cadeia de suprimentos: planejamento do fluxo de produtos e dos recursos. São Paulo: Atlas, 2003.

LAURINDO, Fernando J. Barbin. Tecnologia da Informação: eficácia nas organizações. São Paulo: Futura, 2002.

SALES, Alessandra Simoni Ferraz; FERREIRA, Marilene Lopes. Gestão Estratégica da Informação na Logística. REUNA: Revista de Economia da UNA, v. 7, n. 2, abr.jun. 2000.

SEBRAE. Serviço Brasileiro de Apoio às Micro e Pequenas Empresas. 10 Anos de Monitoramento da Sobrevivência e Mortalidade de Empresas. 2008. Disponível em: https://m.sebrae.com.br/Sebrae/Portal\%20Sebrae/UFs/SP/Pesquisas/10_anos_mortalidade_rel atorio_completo.pdf. Acesso em: 20 jun. 2020. 